\title{
The cloud and its silver lining: negative and positive spillovers from automotive recalls
}

\author{
Verdiana Giannetti ${ }^{1}$ - Raji Srinivasan ${ }^{2}$
}

Accepted: 5 April 2021 / Published online: 28 April 2021

(C) The Author(s) 2021

\begin{abstract}
Product recalls hurt the sales of non-recalled products in the category because of negative spillovers. Recently, there has been some evidence of positive spillovers from recalls on the sales of non-recalled products. We focus on spillovers from brand- (i.e., same brand), firm- (i.e., same firm, but not same brand), and countrylevel (i.e., same country-of-origin, but not same firm) recalls on the sales of nonrecalled products. Furthermore, we examine how advertising and price of nonrecalled products interact with brand-, firm-, and country-level recalls to affect their sales. We use data on 124 cars in the USA in 2006-2015. Results indicate that brand-level (country-level) recalls hurt (benefit) the sales of non-recalled products. Higher advertising and price of non-recalled products weaken the negative effect of brand-level recalls, while lower advertising and price strengthen the positive effect of country-level recalls. Finally, firm-level recalls result in positive spillovers when advertising is high.
\end{abstract}

Keywords Product recalls · Spillovers · Country-of-origin · Automotive industry

\section{Introduction}

Product recalls hurt the sales of recalled products and of some non-recalled products in the category because of negative spillovers (Cleeren et al., 2013). Furthermore, as products in a category are substitutes, recalls may, sometimes, benefit the sales of non-recalled products.

Verdiana Giannetti

v.giannetti@leeds.ac.uk

Raji Srinivasan

raji.srinivasan@mccombs.utexas.edu

1 Marketing Division, Leeds University Business School, University of Leeds, Maurice Keyworth Building, Moorland Rd, Leeds LS2 1AN, UK

2 Red McCombs School of Business, University of Texas at Austin, 2110 Speedway, Stop B6000, Austin, TX 78712, USA 
Research has examined the negative effects of recalls on recalled products (Cleeren et al., 2008). A narrower stream of research indicates that recalls result in negative spillovers for products which are similar to the recalled ones (Borah \& Tellis, 2016). There is also some evidence of positive spillovers (Zhao et al., 2011). Borah \& Tellis (2016) find that negative online chatter following a car's recall increases the sales of its nearest rival from another country. This suggests a role for products' country-of-origin (COO) in this context.

We focus on spillovers from brand- (i.e., same brand), firm- (i.e., same firm, but not same brand), and country-level (i.e., same COO, but not same firm) recalls on the sales of a non-recalled product in the category. Furthermore, we examine how advertising and price of the non-recalled product moderate these spillovers.

We select the US passenger cars industry as the empirical context. The data include 124 cars in 2006-2015.

This study has three contributions. First, it shows that COO plays a different role in recalls' spillovers than previously suggested. Second, while the literature focused primarily on the marketing mix of recalled products, we consider the marketing mix of non-recalled products. Third, this research is the first to examine spillovers at multiple product hierarchy levels, i.e., brand, firm, and COO. The findings are useful to managers to understand how a (non-recalled) product's advertising and price moderate the effects of other products' recalls on its sales.

\section{Hypotheses}

\subsection{Definitions}

The term "product" (or "make-model"1) refers to a specific car (e.g., Toyota Camry). The term "brand" (or "make") refers to a family of products with a brand name (e.g., Toyota). The term "firm" refers to the manufacturer (e.g., Toyota Motor Corporation). Finally, the term "COO" refers to the country-of-origin of the firm (e.g., Japan).

Using a product as unit of analysis, "brand-level recalls" are recalls of products of the same brand as the focal product, "firm-level recalls" are recalls of products of other brands of the same firm as the focal product, and "country-level recalls" are recalls of products of other firms from the same $\mathrm{COO}$ as the focal product. If Toyota Camry is the focal product, the recall of Toyota Corolla is a brand-level recall, the recall of Lexus ES is a firm-level recall, and the recall of Honda Accord is a country-level recall.

\subsection{Main effects}

We rely on two theories. First, consideration set formation theory (Hauser, 2014), which posits that consumers, when considering a purchase, first form a

\footnotetext{
1 Past research on the automotive industry used make-model and nameplate interchangeably.
} 
consideration set of products and then choose a product from this set. Second, accessibility-diagnosticity theory (Feldman \& Lynch, 1988), which posits that, if a consumer thinks product $\mathrm{A}$ is informative about product $\mathrm{B}$, she will use information about $\mathrm{A}$ to make inferences about $\mathrm{B}$.

Brand-level Applications of the accessibility-diagnosticity theory to recalls (Roehm $\&$ Tybout, 2006) indicate that, when a recall is revealed, its effects are reflected not only on the recalled product but also on non-recalled products similar to it on aspects related to the recall (e.g., materials, plants, etc.) (Borah \& Tellis, 2016). Products of the same brand share the same materials, plants (Hora et al., 2011), and esthetic features (e.g., BMW Kidney Grille). A recall will change the consideration set of consumers willing to buy the recalled product or a product similar to it. Consequently, consumers may exclude from (not include in) their consideration set (Palazzolo \& Feinberg, 2015) the non-recalled product of the recalling brand, as they may consider it likely to incur recalls itself. Hence, brand-level recalls will decrease the sales of the non-recalled product. We do not formally hypothesize this relationship, given the extensive evidence for it in the literature (Liu \& Shankar, 2015).

Country-level A product's COO may affect consumers' evaluations of specific attributes (Johansson et al., 1985). As an example, German cars are considered fuelefficient, while US cars are considered powerful (Erickson et al., 1984). However, a product's COO influences consumers' purchase decisions only when information is unclear (Verlegh et al., 2005), serving as a heuristic under conditions of uncertainty.

When a product from a given $\mathrm{COO}$ is recalled, consumers who had previously included it in their consideration sets may no longer do so along with other products of the same brand. As a result, they will engage in a consideration set substitution process (Palazzolo \& Feinberg, 2015). Consumers may rely on a heuristic to develop their new consideration sets (Maheswaran, 1994) and include products from the same $\mathrm{COO}$ as the recalled product, expecting them to be similar on desirable attributes (Johansson et al., 1985) to the excluded products. Anecdotal evidence supports this mechanism. In 2010, sales of Toyota make-models recalled for accelerator problems were down $13 \%$. Toyota Camry midsize sedan, usually the best-selling car in the USA, recorded a $20 \%$ decrease being outsold by the equally Japanese Honda Accord (Bunkley, 2010). Hence:

$\mathrm{H}_{1}$ : The higher the number of country-level recalls, the higher the sales of a non-recalled product from the country.

We note that this logic runs contrary to Borah and Tellis (2016), who argue that consumers make similarity inferences for products from the same $\mathrm{COO}$ as they expect them to have similar processes of product development, so that country-level recalls will lead to negative spillovers. We suggest that this may not be the case as this mechanism is more likely to occur at the brand-level. Different firms from the same $\mathrm{COO}$ do not necessarily share suppliers nor processes, crucial aspects when 
consumers evaluate a non-recalled product's likelihood to incur recalls. Moreover, products from the same $\mathrm{COO}$ are often perceived as sharing attributes such as driving comfort (Erickson et al., 1984; Johansson et al., 1985), being substitutes in consumers' consideration sets.

Firm-level At first blush, it may appear that the mechanism discussed above for brand-level recalls also applies to firm-level recalls. The negative information of a recall may be regarded as diagnostic of non-recalled products of the same firm. Hence, firm-level recalls may decrease the sales of a non-recalled product. However, other reasons suggest the opposite. First, brands are often managed autonomously from firms (Kalaignanam et al., 2013), sharing neither ownership, production processes, nor materials. As a result, negative information of a recall may not spill over to non-recalled products of other brands of the same firm. Second, consumers may not be able to ascribe each brand to its firm. This is particularly true in the automotive industry (Gorzelany, 2019). If consumers are not aware of the branding structure in the category, they may assume the industry has only three levels, i.e., product, brand, and COO. As a result, they may (mis)interpret firm-level recalls as country-level recalls. Due to these countervailing mechanisms, we remain agnostic on the nature of the effects of firm-level recalls.

\subsection{Interaction effects}

We expect brand-level recalls to differ from country-level recalls on a key aspect. When a product of a given brand is recalled, consumers may consider negative information diagnostic not only of the recalled product but also of non-recalled products of the same brand, whose perceived quality will be negatively affected. Conversely, negative information may not be considered diagnostic of non-recalled products of different firms from the same COO. Such products' perceived quality will not be negatively affected (see $\mathrm{H}_{1}$ ). Against this backdrop, we formulate the hypotheses for the interaction effects.

\subsubsection{Brand-level}

Advertising Advertising is a signal of quality and can differentiate the non-recalled product from the recalled products of the same brand (Xiong \& Bharadwaj, 2013). As Roehm and Tybout (2006) note, when consumers are primed to consider differentiation across products, the recalled product is isolated from non-recalled products. Thus, advertising may help the non-recalled product to be retained in the consumer's consideration set, by signaling its superior quality with respect to the recalled products of the same brand. Hence:

$\mathrm{H}_{2 \mathrm{adv}}$ : The higher the advertising of a non-recalled product, the weaker the negative effect of brand-level recalls on its sales. 
Price As with advertising, price is also a signal of quality (Blattberg \& Wisniewski, 1989). As recalls make safety more salient to consumers (Chen et al., 2019), and consumers grow less price-sensitive (Zhao et al., 2011), consumers may interpret a lower price, following brand-level recalls, as a signal of low quality as, as mentioned above, non-recalled products are expected to incur recalls when products of the same brand are recalled. Hence, we reason that, among products of the same brand as the recalled products, those with a higher price will be more likely to be included in (chosen from) the consideration set. A higher price, in fact, may be perceived as a signal that the non-recalled product is of higher quality compared to the recalled products of the same brand, weakening the negative effect of brand-level recalls. Anecdotal evidence supports this mechanism. In 2015, in the 2 months following Honda's recall of Accord and Civic due to airbag problems, discounts for the non-recalled Honda Fit were more than halved, resulting in a substantially higher price for consumers. Hence:

$\mathrm{H}_{2 \text { price }}$ : The higher the price of a non-recalled product, the weaker the negative effect of brand-level recalls on its sales.

\subsubsection{Country-level}

Advertising We expect opposing effects here. On the one hand, higher advertising may signal the quality of non-recalled products from the same $\mathrm{COO}$ as the recalled products to consumers who have grown more concerned about quality following recalls. On the other hand, however, inferred motivations may influence the effectiveness of advertising (Eagly et al., 1978). Higher advertising following country-level recalls may backfire as consumers believe this to be an opportunistic attempt to take advantage of the misfortune of the recalling brand (Cleeren, 2015; Cleeren et al., 2013; Siomkos et al., 2010), lowering product evaluations. This may explain why advertising for Honda Accord went down in the months following the 2010 Toyota recalls. We expect the second mechanism to outweigh the first as, as mentioned above, countrylevel recalls should not raise concerns regarding the quality of non-recalled products and their likelihood to incur recalls. ${ }^{2}$ Consistent with this reasoning, we expect higher advertising to weaken the positive effect of country-level recalls. Hence:

$\mathrm{H}_{3 \mathrm{adv}}$ : The higher the advertising of a non-recalled product, the weaker the positive effect of country-level recalls on its sales.

\footnotetext{
${ }^{2}$ In sum, while we expect a positive main effect of advertising on sales as advertising is a signal of quality, we do not expect this mechanism to be manifest in an interaction with country-level recalls. Conversely, we expect the positive effect of advertising to be weakened as country-level recalls increase.
} 
We do not expect this mechanism to hold for brand-level recalls. In the case of brand-level recalls, the non-recalled product is of the recalling brand and, as a result, cannot be considered opportunistic.

Price Again, we expect opposing effects. On the one hand, a higher price may signal the quality of non-recalled products from the same $\mathrm{COO}$ as the recalled products to consumers who have grown more concerned about quality following recalls. Furthermore, as inferred motivations may influence the effectiveness of price reductions (Campbell, 1999), a lower price following country-level recalls may backfire as consumers believe this to be an opportunistic attempt to take advantage of the misfortune of the recalling brand (Chen et al., 2019; Cleeren, 2015; Cleeren et al., 2013; Siomkos et al., 2010), lowering product evaluations. As an example, the executive VP of Honda's US subsidiary told dealers, after Toyota's 2010 recalls: "We will not react in a predatory way towards either Toyota or Toyota customers" (Simon \& Jung-a, 2010). On the other hand, however, a lower price of the non-recalled product may strengthen the positive effect of country-level recalls, as consumers may choose, among products from the same $\mathrm{COO}$ as the recalled products, the one that offers superior value, i.e., a lower price. We expect this mechanism to outweigh the previous as country-level recalls, differently from brand-level recalls, should not raise concerns regarding the quality of non-recalled products and their likelihood to incur recalls. ${ }^{3}$ Consistent with this reasoning, we expect a higher price to weaken the positive effect of country-level recalls. Hence:

$\mathrm{H}_{3 \text { price: }}$ The higher the price of a non-recalled product, the weaker the positive effect of country-level recalls on its sales.

For the reasons mentioned above regarding the main effect of firm-level recalls, we remain agnostic on the interaction effects of firm-level recalls.

\section{Method}

\subsection{Data}

We use the US passenger cars industry as the context as numerous make-models can be targets of spillovers at any point in time. Passenger cars' recalls are highly publicized events resulting in consumers' awareness (PMI, 2015).

We collected data on passenger cars' recalls in 2005-2014 from the NHTSA. ${ }^{4}$ To focus on recalls of (substantive) brands, we included 21 large brands. These brands constitute more than $90 \%$ of the sales of passenger cars in each year in 2006-2015.

\footnotetext{
${ }^{3}$ In sum, we do not expect a lower price to be interpreted as a signal of low quality against the backdrop of country-level recalls.

${ }^{4}$ https://www.nhtsa.gov/recalls.
} 
We excluded make-models priced over US $\$ 150,000$ because they are unlikely to be in the consideration set of mainstream shoppers (see Liu et al., 2017 for a similar logic). As only sufficiently large recalls are likely to affect perceptions, we excluded recalls involving less than 15,000 units. Smaller recalls typically involve batches produced in specific plants during circumscribed periods (see Cleeren et al., 2013 for a similar logic). When the database contained multiple recalls for the same make-model in a month, to avoid overcounting, we only considered one recall (Thirumalai \& Sinha, 2011).

We collected monthly sales volumes for all make-models in 2006-2015 from Wards' Auto. Wards provides data on attributes, annual manufacturer-suggested retail list prices (MSRP), and monthly promotions. Furthermore, we collected data on make-model monthly advertising from Kantar.

Finally, for each month, we excluded all make-models that were recalled at least once in the previous (rolling) year. This allows us to distinguish the effects of other make-models' recalls from those of the focal make-model. The final sample is a panel of 4744 make-model-months in 2006-2015. For a list of make-models, see Table A1, Web Appendix A. There are 559 recalls in our sample. On average, each month, 4.37 make-models are recalled. Furthermore, each month, there are, on average, 0.24 recalls per brand, 0.35 per firm, and 0.89 per COO.

\subsection{Measures}

We provide the descriptions for variables in Table 1 and, in Table B1, Web Appendix B, the descriptives and correlations. All VIFs are below 10.

\subsection{Estimation}

As data are nested (make-model-month observations are nested in brands, which are nested in firms, which are nested in COOs), we estimate a random intercepts mixed model. Following prior research (Liu \& Shankar, 2015; Liu et al., 2017), we consider attributes (e.g., horsepower, size) to be exogenous. In the automotive industry, in fact, attributes are redesigned when a new make-model is introduced, approximately every 5 years (Palazzolo \& Feinberg, 2015). This assumption is reasonable, as firms cannot change the attributes of cars in the short-term (Sudhir, 2001).

Advertising and price are presumably endogenous as make-model-level omitted variables may affect both marketing mix and sales. Please see Web Appendix C for a discussion of how we mitigate endogeneity concerns using a control function approach (Petrin \& Train, 2010).

We estimated the following equation:

Sales $_{t}=\mu_{0}+\mu_{1}$ brand-level recalls ${ }_{(t-1-t-12)}+\mu_{2}$ country-level recalls ${ }_{(t-1-t-12)}+\mu_{3}$ firmlevel recalls ${ }_{(t-1-t-12)}+\mu_{4}$ advertising $_{(t-1-t-12)}+\mu_{5}$ price $_{(t-1)}+\mu_{6}$ brand-level recalls $_{(t-1-t-12)}$ $\times$ advertising $_{(t-1-t-12)}+\mu_{7}$ brand-level recalls $_{(t-1-\mathrm{t}-12)} \times$ price $_{(t-1)}+\mu_{8}$ country-level recalls $_{(t-1-t-12)} \times$ advertising $_{(t-1-t-12)}+\mu_{9}$ country-level recalls $_{(t-1-t-12)} \times$ price $_{(t-1)}+\mu_{10}$

\footnotetext{
${ }^{5}$ In the interest of brevity, we remove the subscript ibfc, where $i$ represents make-models, $b$ brands, $f$ firms, and $c \mathrm{COOs}$, from the variables.
} 


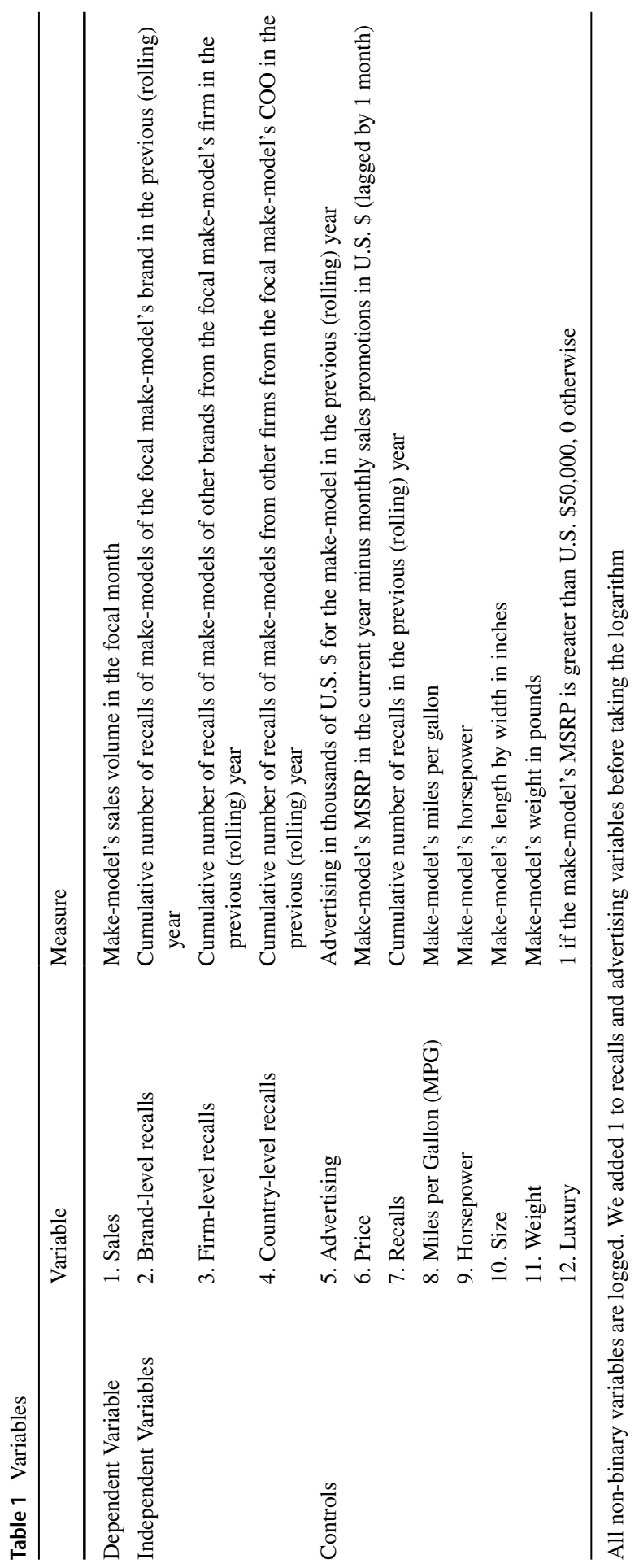


firm-level recalls ${ }_{(t-1-t-12)} \times$ advertising $_{(t-1-t-12)}+\mu_{11}$ firm-level recalls ${ }_{(t-1-t-12)} \times$ price $_{(t-1)}+$ $\sum_{f=12}^{17} \mu_{f}$ controls $_{t}+\mu_{18} \varepsilon_{A 1 t}+\mu_{19} \varepsilon_{A 2 t}+$ year FEs + month FEs + random effects $+\varepsilon_{1 t}$. where $\mu$ s are parameter estimates, subscript $t$ months, $\varepsilon_{A 1 t} \mathrm{~s}-\varepsilon_{A 2 t} \mathrm{~s}$ the errors from equations c1-c2 (see Web Appendix C), and $\varepsilon_{1 \mathrm{t}}$ observational error. The model includes random effects for $\mathrm{COO}$, firm, brand, and make-model. Potentially endogenous variables are lagged by 1 month. Standard errors are bootstrapped (200 replications).

\section{Results}

We report a main effects' model in column 1, Table 2. In column 2 we include control variables. We report the results for the main model in column 3 (log likelihood $=-5078.75)$. Brand-level recalls decrease the sales of the non-recalled product $(b=-0.73, p<0.05)$, while country-level recalls increase them $(b=1.62, p<0.01)$ in support of $\mathrm{H}_{1}$. There is no effect of firm-level recalls $(b=-0.70, p>0.10)$.

Advertising $(b=0.01, p<0.05)$ and price $(b=0.06, p<0.05)$ of the non-recalled product weaken the negative effect of brand-level recalls, in support of $\mathrm{H}_{2 \mathrm{adv}}$ and $\mathrm{H}_{2 \text { price }}$. Furthermore, advertising $(b=-0.02, p<0.01)$ and price $(b=-0.13$, $p<0.01)$ of the non-recalled product weaken the positive effect of country-level

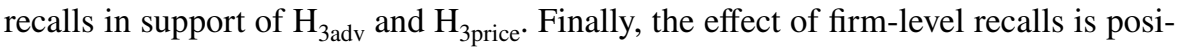
tive when advertising is high $(b=0.04, p<0.01)$. The interaction between price and firm-level recalls is not significant $(b=0.03, p>0.10)$. We display the marginal effects for the interactions in Figure D1, Web Appendix D. We report robustness checks in Web Appendix E.

\section{Discussion}

The findings extend the recalls literature. First, while research focused on the effects of recalls on recalled products, we extend the narrower literature on spillovers, which has hitherto focused on negative spillovers (see e.g., Van Heerde et al., 2007). In doing so, we develop a comprehensive model of the effects of recalls by focusing on both negative and positive spillovers. Consistent with previous research (Liu \& Shankar, 2015), the findings indicate that brand-level recalls reduce the sales of non-recalled products. Furthermore, country-level recalls increase the sales of nonrecalled products. In doing so, we identify a silver lining and, indeed, an opportunity for non-recalled products in the face of country-level recalls. The finding extends the literature on $\mathrm{COO}$ effects by showing that they play a different role than previously suggested. The results apparently contradict Borah and Tellis (2016), as discussed above; we conjecture that our focus on sales (vs. online chatter) may explain this divergence. Furthermore, our examination relies on a substantially different sample and timeframe.

Second, we depart from the literature, which focused on how recalled products can use their marketing mix. In doing so, we focus on how the marketing mix of non-recalled products can weaken (strengthen) negative (positive) spillovers. 
Table 2 Random intercepts mixed model

\begin{tabular}{|c|c|c|c|c|}
\hline & \multicolumn{3}{|c|}{ Dependent variable: sales } & \multirow{3}{*}{$\begin{array}{l}\text { Column } 4 \\
\text { Hypothesized effects }\end{array}$} \\
\hline & Column 1 & Column 2 & Column 3 & \\
\hline & \multicolumn{3}{|c|}{ Unstandardized coefficients (SE) } & \\
\hline Brand-level recalls & $-.04(.02)^{* *}$ & $-.05(.02)^{* *}$ & $-.73(.29)^{* *}$ & \\
\hline Country-level recalls $\left(\mathrm{H}_{1}\right)$ & $.07(.02)^{* * *}$ & $.16(.02)^{* * *}$ & $1.62(.38)^{* * *}$ & + \\
\hline Firm-level recalls & $-.13(.03)^{* * *}$ & $-.03(.03)$ & $-.70(.61)$ & \\
\hline Advertising & & $.25(.02)^{* * *}$ & $.26(.02)^{* * *}$ & \\
\hline Price & & $-2.52(.17)^{* * *}$ & $-2.25(.21)^{* * *}$ & \\
\hline $\begin{array}{l}\text { Brand-level recalls } \times \text { adver- } \\
\text { tising }\left(\mathrm{H}_{2 \mathrm{adv}}\right)\end{array}$ & & & $.01(.005)^{* *}$ & + \\
\hline $\begin{array}{l}\text { Brand-level recalls } \times \text { price } \\
\left(\mathrm{H}_{2 \text { price }}\right)\end{array}$ & & & $.06(.03)^{* *}$ & + \\
\hline $\begin{array}{l}\text { Country-level recalls } \times \text { adver- } \\
\text { tising }\left(\mathrm{H}_{3 \mathrm{adv}}\right)\end{array}$ & & & $-.02(.01)^{* * *}$ & - \\
\hline $\begin{array}{l}\text { Country-level recalls } \times \text { price } \\
\left(\mathrm{H}_{3 \text { price }}\right)\end{array}$ & & & $-.13(.04)^{* * *}$ & - \\
\hline $\begin{array}{l}\text { Firm-level recalls } \times \text { advertis- } \\
\text { ing }\end{array}$ & & & $.04(.01)^{* * *}$ & \\
\hline Firm-level recalls $\times$ price & & & $.03(.06)$ & \\
\hline Recalls & & $-.06(.05)$ & $-.05(.05)$ & \\
\hline MPG & & $.97(.20)^{* * *}$ & $.98(.20)^{* * *}$ & \\
\hline Horsepower & & $1.55(.18)^{* * *}$ & $1.59(.18)^{* * *}$ & \\
\hline Size & & $.90(.43)^{* *}$ & $1.01(.44)^{* *}$ & \\
\hline Weight & & $.59(.16)^{* * *}$ & $.43(.16)^{* * *}$ & \\
\hline Luxury & & $.08(.07)$ & $.09(.08)$ & \\
\hline Error-advertising & & $-.17(.02)^{* * *}$ & $-.16(.02)^{* * *}$ & \\
\hline Error-price & & $2.46(.27)^{* * *}$ & $2.42(.28)^{* * *}$ & \\
\hline Observations & 5868 & 4744 & 4744 & \\
\hline Log likelihood & -7337.78 & -5114.87 & -5078.75 & \\
\hline
\end{tabular}

$p<.10 . * * p<.05 . * * * p<.01$. Regressions include a constant. Year- and month-fixed effects and random effects at the make-model, brand, firm, and COO levels are included. Bootstrapped standard errors

Third, this research is the first to separately examine the effects of other products' recalls at multiple hierarchical levels in a category. While brand- (Roehm \& Tybout, 2006) and firm-level (Zavyalova et al., 2012) recalls have been investigated, past research has not distinguished them. Distinguishing across brand-, firm-, and country-level recalls allows to disentangle how non-recalled products with different degrees of relatedness to the recalled product are likely to experience spillovers. We show that perceived similarity on processes of product development, which we expect at the brand-level, leads to negative spillovers, as consumers will consider a product that shares product development processes with the recalled product likely to have defects. Conversely, perceived similarity on relevant attributes (e.g., driving comfort), which we expect at the country-level, 
leads to positive spillovers, as consumers will consider a product with the same desirable attributes as the recalled product a good substitute for it.

For managerial practice, managers are likely aware that brand-level recalls decrease the sales of a non-recalled product. However, higher advertising weakens such negative effect by signaling that the non-recalled product is different from the recalled one. Furthermore, a higher price shields the non-recalled product from the negative effects of brand-level recalls by reaffirming its quality (interestingly, the marginal effects show that, for expensive products, the effect of brand-level recalls can be positive). Such findings are useful when multiple products are offered under the same brand, as they allow managers to effectively weather the negative consequences of brand-level recalls.

Furthermore, managers should be cognizant that country-level recalls increase the sales of the non-recalled product. Lower advertising and price enhance the positive effect of country-level recalls on the sales of the nonrecalled product. This is useful when products from a given $\mathrm{COO}$ are characterized by attribute-related stereotypes (e.g., US appliances, Japanese electronics).

The findings show that, at the aggregate level, firm-level recalls do not affect the sales of non-recalled products. We reason that only some consumers know which firm owns a brand. For them, firm-level recalls display a negative effect, paralleling brand-level recalls. Conversely, for consumers who are not aware of the branding hierarchy in the category, firm-level recalls display a positive effect, paralleling country-level recalls. Interestingly, the marginal effects show that the effect of firm-level recalls turns from negative to positive as advertising increases. We argue that, from a tactical perspective, managers in the automotive industry should try not to emphasize the parent firm of their brand in their communication efforts, instead emphasizing its COO. If a make-model of another brand from the focal firm is recalled, in fact, make-models of the focal brand will be shielded by negative spillovers. Instead, they will experience positive spillovers, as the recall will be interpreted as a country-level recall.

The findings generate implications for policy-makers. Some recalls are particularly severe and may damage the economy of a country. We show that, even when a recall involves products from a given $\mathrm{COO}$, nothing is lost as non-recalled products from the same $\mathrm{COO}$ can benefit from it.

Due to the peculiarities of the automotive industry, future research investigating the generalizability of our findings will be useful.

Supplementary Information The online version contains supplementary material available at https://doi. org/10.1007/s11002-021-09568-6.

Open Access This article is licensed under a Creative Commons Attribution 4.0 International License, which permits use, sharing, adaptation, distribution and reproduction in any medium or format, as long as you give appropriate credit to the original author(s) and the source, provide a link to the Creative Commons licence, and indicate if changes were made. The images or other third party material in this article are included in the article's Creative Commons licence, unless indicated otherwise in a credit line to the material. If material is not included in the article's Creative Commons licence and your intended use is not permitted by statutory regulation or exceeds the permitted use, you will need to obtain permission directly from the copyright holder. To view a copy of this licence, visit http://creativecommons.org/licen ses/by/4.0/. 


\section{References}

Blattberg, R. C., \& Wisniewski, K. J. (1989). Price-induced patterns of competition. Marketing Science, $8,291-309$

Borah, A., \& Tellis, G. J. (2016). Halo (Spillover) Effects in social media: Do product recalls of one brand hurt or help rival brands? Journal of Marketing Research, 53, 143-160

Bunkley, N. (2010, March 2). After recalls, Toyota Offers incentives to win back wary customers. Retrieved from: https://www.nytimes.com/2010/03/03/business/03auto.html. Accessed 27 Apr 2018.

Campbell, M. (1999). Why did you do that? The important role of inferred motive in perceptions of price fairness. Journal of Product \& Brand Management, 8, 145-152

Chen, Z., Sridhar, S., Becerril-Arreola, R., Cui, T. H., \& Dong, Y. (2019). Promotions as competitive reactions to recalls and their consequences. Journal of the Academy of Marketing Science, 47, $702-722$

Cleeren, K. (2015). Using advertising and price to mitigate losses in a product-harm crisis. Business Horizons, 58, 157-162

Cleeren, K., Van Heerde, H. J., \& Dekimpe, M. G. (2013). Rising from the Ashes: How brands and categories can overcome product-harm crises. Journal of Marketing, 77, 58-77

Cleeren, K., Dekimpe, M. G., \& Helsen, K. (2008). Weathering product-harm crises. Journal of the Academy of Marketing Science, 36, 262-270

Eagly, A. H., Wood, W., \& Chaiken, S. (1978). Causal inferences about communicators and their effect on opinion change. Journal of Personality and Social Psychology, 36, 424-435

Erickson, G. M., Johansson, J. K., \& Chao, P. (1984). Image variables in multi-attribute product evaluations: Country-of-origin effects. Journal of Consumer Research, 11, 694-699

Feldman, J. M., \& Lynch, J. G., Jr. (1988). Self-generated validity and other effects of measurement on belief, attitude, intention, and behavior. Journal of Applied Psychology, 73, 421-435

Gorzelany, J. (2019, July 12). Who owns which car brands. Retrieved from: https://www.forbes.com/sites/ jimgorzelany/2019/07/12/who-owns-which-car-brands/\#136127f65ea7. Accessed 25 Feb 2020.

Hauser, J. R. (2014). Consideration-set heuristics. Journal of Business Research, 67, 1688-1699

Hora, M., Bapuji, H., \& Roth, A. V. (2011). Safety hazard and time to recall: The role of recall strategy, product defect type, and supply chain player in the U.S. Toy industry. Journal of Operations Management, 29, 766-777

Johansson, J. K., Douglas, S. P., \& Nonaka, I. (1985). Assessing the impact of country of origin on product evaluations: A new methodological perspective. Journal of Marketing Research, 22, 388-396

Kalaignanam, K., Kushwaha, T., \& Eilert, M. (2013). the impact of product recalls on future product reliability and future accidents: Evidence from automobile industry. Journal of Marketing, 77, 41-57

Liu, Y., Shankar, V., \& Yun, W. (2017). Crisis management strategies and the long-term effects of product recalls on firm value. Journal of Marketing, 81, 30-48

Liu, Y., \& Shankar, V. (2015). The dynamic impact of product-harm crises on brand preference and advertising effectiveness: An empirical analysis of the automobile industry. Management Science, $61,2514-2535$

Maheswaran, D. (1994). Country of origin as a stereotype: The effects of consumer expertise and attribute information on product evaluations. Journal of Consumer Research, 21, 354-365

Palazzolo, M., \& Feinberg, F. (2015). Modeling consideration set substitution. Unpublished Paper. Retrieved from: http://www-personal.umich.edu/ palazzom/JMP_Palazzolo_Consideration_Set_ Substitution.pdf. Accessed 25 Nov 2020.

Petrin, A., \& Train, K. (2010). A control function approach to endogeneity in consumer Choice Models. Journal of Marketing, 47, 3-13

PMI (2015). The impact of automotive recalls on consumer opinion. Retrieved from: https://www.phoen ixmi.com/wp-content/uploads/2017/09/The-Impact-of-Automotive-Recalls-on-Consumer-OpinionInfegy-PMI-.pdf. Accessed 11 Jul 2020.

Roehm, M. L., \& Tybout, A. M. (2006). When Will a brand scandal spill over, and how should competitors respond? Journal of Marketing Research, 43, 366-373

Simon, B., \& Jung-a, S. (2010, Feb 17). Carmakers to take advantage of toyota recalls. Retrieved from: https://www.ft.com/content/122c09f4-1bef-11df-a5e1-00144feab49a. Accessed 8 May 2017.

Siomkos, G., Triantafillidou, A., Vassilikopoulou, A., \& Tsiamis, I. (2010). Opportunities and threats for competitors in product-harm crises. Marketing Intelligence \& Planning, 28, 770-791 
Sudhir, K. (2001). Competitive pricing behavior in the auto market: A structural analysis. Marketing Science, 20, 42-60

Thirumalai, S., \& Sinha, K. K. (2011). Product recalls in the medical device industry: An empirical exploration of the sources and financial consequences. Management Science, 57, 376-392

Van Heerde, H. J., Helsen, K., \& Dekimpe, M. G. (2007). The impact of a product-harm crisis on marketing effectiveness. Marketing Science, 26, 230-245

Verlegh, P. W. J., Steenkamp, J. E. M., \& Meulenberg, M. T. G. (2005). Country-of-origin effects in consumer processing of advertising claim. International Journal of Research in Marketing, 22, 127-139

Xiong, G., \& Bharadwaj, S. (2013). Asymmetric roles of advertising and marketing capability in financial returns to news: Turning bad into good and good into great. Journal of Marketing Research, 50, $706-724$

Zavyalova, A., Pfarrer, M. D., Reger, R. K., \& Shapiro, D. L. (2012). Managing the message: The effects of firm actions and industry spillovers on media coverage following wrongdoing. Academy of Management Journal, 55, 1079-1101

Zhao, Y., Zhao, Y., \& Helsen, K. (2011). Consumer Learning in a turbulent market environment: Modeling consumer choice dynamics after a product-harm crisis. Journal of Marketing Research, 48, 255-267

Publisher's Note Springer Nature remains neutral with regard to jurisdictional claims in published maps and institutional affiliations. 